\title{
Research on the Construction of the College English Teaching Model That Base on the POA Theory and Its Empirical Study
}

\author{
Lijuan Zhang \\ Xi'an International University, Xi'an Shaanxi, 710077
}

Keywords: POA Theory; Teaching Model; Empirical Study

\begin{abstract}
As the important part of the college education, college English teaching influences the students' professional abilities a lot. The colleges are the cultivating bases that provide the high-quality talents to the society; they must clearly realize that the social circumstance and the economic circumstance are changing rapidly, and then adjust the developmental model of education timely. At the some time, the colleges should carry out the educational reform so as to change the present educational situation that it is waste of time and inefficient, and to cultivate the more professional students and improve the students' English applied abilities. Currently, because of some realistic reasons during the development process, there are some defects in English teaching, so it needs to be improved and perfected during the development process. The teachers must explore the new teaching model so as to improve the overall quality and the professional quality of the students. The POA theory not only provides the new ideas to the English teaching, but also is a breakthrough of the educational reform. According to the relevant documents, the writer of this thesis starts from the conception of the POA theory, and then discusses and researches the construction of the college English teaching model according to the POA theory.
\end{abstract}

\section{Introduction}

As the important part of the quality education, the construction of the new English teaching system is very significant to the English learning; it is not only the important method to cultivate the inter-disciplinary talents, but also the important approach that optimizes and integrates the teaching methods. To integrate the POA theory with the English teaching is a important mean of development on the English teaching. In the new times, how to find out the weakness of us, and how to ensure the developmental direction of us under the background of the educational reform and the structural reform, these have become the key factors that influence the development of the college English. In the present construction of the innovation on English teaching model, there are still many problems, such as the teaching models are rigid, emphasizing theories but neglecting practice, the system of teaching is defective, etc. How to enrich ourselves and find out the new developmental directions of English in the new situation, then to master and develop the POA theory, at the some time, to reconstruct and innovate the teaching models according to the POA theory have become the very issues that we have to think about a lot.

\section{The conception of the POA theory.}

POA is the abbreviation of "production-oriented approach", it brings the new ideas to the reform of the college English teaching. This theoretical system includes there parts: (1) Teaching Philosophy. The Teaching Philosophy includes "Learning Center", "Integration of Learning and Application”, and "Overall Education”. "Learning Center", which supports that the schools should launch the teaching activities that are planned and organized in advance so as to improve the students' learning efficiency, this philosophy challenges the philosophy that "takes the students as the center"; "Integration of Learning and Application" proposes to integrate the input with the 
output, and integrate the learning and the application, so as to cultivate the overall language applied abilities of the students ${ }^{[1]}$; “Overall Education" emphasizes that the foreign language are not only a kind of tool, but also an approach to understand the cultures that are relate to the languages. The teachers should choose the materials that could not only improve the students' foreign language abilities, but also their qualities of humanity. (2) Teaching Supposition. Teaching Supposition includes "Output Motivating”, "Input Enabling”, "Selective Learning”, and "Assessment Promoting Learning”. This supposition overturns the traditional teaching order, i.e., "out put is behind input" instead of the new conception that is "output $\rightarrow$ input $\rightarrow$ output". This supposition also brings out that the production are not only the motivation of the language learning, but also the goal of the learning, the teachers should play a leading role and provide the proper input materials to the students, and guide the students to learn the materials that has been selected out, so as to "learn the knowledge that could be applied in the practice, improve the practice abilities of the students by the knowledge they have learned, and apply the knowledge they have learned to the practice", and to improve the students' abilities of expression ${ }^{[2]}$. (3) Teaching Procedure. The teaching Procedure includes three stages that are "Motivating", "Enabling", and "Assessment". In the teaching that is according to the POA theory, the teachers should program the output tasks that simulate the realistic communicative circumstance, and that are challenging to the students; and then, the teachers should choose the necessary input materials according to the needs of the students; at last, the teachers and the students should assess the results of the tasks together ${ }^{[3]}$.

\section{Research on the construction of the college English teaching model that base on the POA theory and its empirical study}

In order to construct the new model, the teachers should be familiar with the actual situations of the students first; and then, choose the input tasks according to the actual situations of the students. The tasks should be attractive and stressful for the students to some extent, so as to arouse the students' desires of exploring the topics of the tasks. To motivate the students' self-learning abilities, it is necessary to let the students have strong interests in English learning. The writer of this thesis designs the task that the students take part in the association activities. The associations are the common organizations in campus, the interpersonal interactions and the tasks often involve lots of topics ${ }^{[4]}$. According to the task, students should follow and report an association activity, and take the communication with the other participators in the activity as their oral task; when the activity is over, the students should fulfill their writing task that is to write a report about the activity, and then to begin the motivating.

After the tasks are assigned, the teachers can not leave the students without any concern immediately; they must pay attention to the fulfilling situations of the students, solve the problems of the students and point out the direction for the students, so as to help the students to fulfill their tasks. The writer of this thesis has set up the requirements of the input according to the association activity that has been mentioned above, so as to ensure the tasks of the students could be fulfilled smoothly.

(1)In the association activity, the students should organize and arrange every participator well, and to communicate with them in correct English, at the some time, the students should distinguish the differences between the writing English and oral English. The teachers should focus on the students' oral English, and discuss the differences between the application of writing English and that of oral English with the students, so as to let the students organize the association activity well.

(2) The students should write a report about the association activity. In one hand, the students should use the correct pattern of report, and to explain and analyze the procedure of the activity in their report; in other hand, the students also should plan the relevant contents of their report, so as to fulfill the tasks that are relate to the outputs. To the tasks that have been programmed by the writer of this thesis, one requirement of the tasks is to ask the students to speak the correct oral English in the activity; the other is to practice their writing abilities by means of writing a report. The teachers could create a simulative social communicative circumstance where the students could exchange their ideas and discuss the topics. For example, by means of the simulative circumstance, the 
students could not only practice their English, but also know how to plan and organize the activity, and how to coordinate and communicate with the participators. After assign the tasks, the teachers must combine the tasks with the textbooks, in addition, they also must give the students the correct guidance, so that the students could improve their English abilities in the correct way, and improve their overall English abilities of every filed, such as vocabulary, grammar, pronunciation, and writing, etc ${ }^{[5]}$.

(3) It is necessary to summarize the words, grammars, pronunciations, and the relevant knowledge on writing that have been involved in the activity, and then the students should learn the knowledge. The teachers should let the students practice their oral English in the simulative social communicative circumstance, provide some relevant materials that are related to the activity to the students, organize and control the activity, and get the relevant materials and information that are related to the students' major together, so as to improve the students' English abilities during the progress of the tasks, and improve the students' social skills and their professional abilities a lot.

As the ultimate stage, the students summarize and demonstrate their studies and the situations of fulfilling the tasks, so as to invite the other students and their teachers to assess their studies. The teachers also should join in the assessment and give some advices and correct the errors of the students, so as to improve the students' English abilities by means of outputting the assessment via the assessment regime. At the some time, it is the important step to integrate the students' English abilities and their professional abilities, and then to make an overall assessment by this assessment regime $^{[6]}$.

(1) To simulate the real circumstance. In this stage, the teachers should arrange the students to practice English in the simulative circumstance by the way of pair work. In the pair work, a student act the organizer of the association activity, this students should program the activity and coordinate the relationship of the participators in the activity; the other student act the participator of the activity, the two students communicate with each other about the procedure and the specific details of the activity. Of course, the contents of the topic should refer to the textbook, and it can not be out of the restriction. In this stage, the students could practice their English abilities by the communication in the simulative circumstance. It is necessary to integrate the contents of the textbook with the communication in the simulative circumstance, so that the students could strengthen their English abilities in the simulative circumstance. We also should notice that it is unpractical to complete the assessment in class because the time in class is limited and the simulative activity spends a lot of time. Therefore, the students could record a video during they complete the activity, then to send the video to their teachers or the other students for comment. The teachers should provide the assessment standard to the students, and then the students should share their experiences via some inactive platforms.

(2) The writing of the report. The students should report the procedure, contents, and the theme of the activity by writing a report. When the students write the reports, their English abilities would be examined. The writing could improve the students' overall English abilities such as their vocabularies, grammars, etc; the students' English abilities could be tested, and then they could improve their weakness that is shown in the activity.

\section{Conclusion}

It is the necessary requirement to reform the rigid traditional educational model that is examination-oriented and the simple teaching model, and then to bring the POA theory into the present English teaching. However, how to introduce and apply the POA theory to the teaching, and how to construct the new model and make some innovations according to the POA theory so as to improve the English abilities of the students are the very issues that we have to discuss seriously. It is the requirement of the times to introduce the POA theory to the English teaching, it is also an important way of improving the efficiency in class and promoting the students become stronger and stronger. For the students, the English teaching should not only just be simple language learning, but also a deeper spiritual learning that aims at improving the students' professional abilities, rebuilding the moral sentiments of the students, and then improve their vocational skills. As the 
places of cultivating the high-quality talents for the society, the colleges should not only teach the theoretical knowledge to the students, but also to cultivate the overall abilities of the students, so as to let the students develop their overall abilities and construct the sound foundation for their career lives by means of practices. Because of the limitations of the writer, the writer of this thesis are still superficial on the POA theory, welcome all the specialists and scholars to enrich this thesis. Thanks!

\section{Acknowledgements}

Pro:The periodical achievement of 2017 planned project approved by the 13th Five-year Plan of Education and Science of Shaanxi Province:the Construction and Empirical Research of College En glish Teaching Mode Based on POA Theory under the Background of the International Talent Culti vation_— Take the Example of Xi'an International University （Project Number:SGH17H421）.

\section{References}

[1]Tang Yanhua. The Inspiration From the English Team Activity that According to the Production-oriented Approach[A]. Research on the education of the Foreign Language and the Innovation on the Development of the Translation(The Sixth Volume)[C]. :2017:3.

[2]Shen Yanfei. The Conception on the Reform of the College English Teaching under the Guidance of the Production-oriented Approach in the Big Data Times[J]. Education Modernization, 2017,(21):23-25.

[3]Liu Xiaoxing, Song Min. The Planning and the Practice of the College Reading and Writing Teaching in the Field of the Production-oriented Approach[J]. Journal of Ningbo Institute of Education, 2017,(02):50-53.

[4]Wang Yingying, Yang Lulu. Research on the English Teaching of the Art College under the Guidance of the Production-oriented Approach ----Take the Unit 4 of the New Horizon College English 1for Example[J]. Journal of Liuzhou Teachers College, 2017,(01):26-29.

[5]Li Chang. Some Deliberations on the Production-oriented Approach that is applied in the College Reading and Writing Teaching in Class[J]. High School Years, 2017,(05):222-223.

[6]Wang Jing. The Exploration on the POA Teaching Model that is Applied in the College Reading, Listening, and Speaking[J]. The Symposium IV of the 2016 International Scholar Symposia that is organized by the Periodical Office of Smart City and the Sino American Academic Exchange Association on the Smart City and the Construction of the Information Technology, 2016:1. 